\title{
História, reforma e lucidez em ciência: A reflexividade científica segundo Pierre Bourdieu
}

History, reform and lucidity/insight in science: Scientific reflexivity according to Pierre Bourdieu

Histoire, réforme et lucidité en science : la réflexivité scientifique selon Pierre Bourdieu

Telmo H. Caria

\section{OpenEdition}

\section{Journals}

Edição electrónica

URL: https://journals.openedition.org/rccs/733

DOI: $10.4000 /$ rccs. 733

ISSN: 2182-7435

\section{Editora}

Centro de Estudos Sociais da Universidade de Coimbra

Edição impressa

Data de publição: 1 dezembro 2007

Paginação: 133-149

ISSN: 0254-1106

\section{Refêrencia eletrónica}

Telmo H. Caria, «História, reforma e lucidez em ciência: A reflexividade científica segundo Pierre Bourdieu», Revista Crítica de Ciências Sociais [Online], 79 | 2007, publicado a 01 outubro 2012 consultado a 21 setembro 2021. URL: http://journals.openedition.org/rccs/733 ; DOI: https://doi.org/ $10.4000 /$ rccs.733 


\title{
História, reforma e lucidez em ciência: A reflexividade científica segundo Pierre Bourdieu
}

\begin{abstract}
Desenvolve-se um comentário crítico ao último livro de Pierre Bourdieu (Science de la science et réflexivité) centrado no entendimento deste autor a propósito da prática científica e da razão (social e cognitiva) da sua crença reflexiva na ciência. Faz-se uma descrição comentada da obra por relação ao património de conhecimentos sociológicos sobre ciência. Põe-se em evidência os principais traços e elementos caracterizadores do habitus científico, na concepção racionalista deste autor, e vinca-se os aspectos em que eles se distanciam da cultura das Ciências Sociais em Portugal. Retira-se consequências desta interpretação, referindo um eventual etnocentrismo da epistemologia bourdiana, porque pouco válida para "nos falar" da ciência fora das Universidades e fora dos países centrais. Adianta-se uma perspectiva sobre a necessidade de "reformar a cultura do campo" das Ciências Sociais em Portugal.
\end{abstract}

Este texto pretende ser, simultaneamente, uma recensão e um comentário crítico ao último escrito de Pierre Bourdieu, na forma de livro, sobre o entendimento deste autor a propósito da prática científica e da razão (social e cognitiva) da sua crença reflexiva na ciência. Refiro-me ao livro de 2001 intitulado Science de la science et réflexivité (Bourdieu, 2001).

De realçar que o meu interesse neste livro não é "inocente", dado visar melhor compreender as concepções de Bourdieu sobre ciência, para poder superar/criticar os limites da sua visão/posição, com o fim de encontrar uma orientação epistemológica complementar que melhor enfatize as virtualidades (cognitiva e social) do método etnográfico para a reflexividade em Ciências Sociais. Lembro que Bourdieu tende a desvalorizar ou a recusar esta metodologia no modo como concebe a reflexividade científica (Bourdieu, 2003: 17-18). Trata-se de uma intencionalidade para o qual este texto pretende apenas contribuir com um pequeno passo, numa caminhada que não sei ainda muito bem como vai ser concluída. Aliás este texto deve ser lido na articulação com duas versões de um outro, anterior, da minha autoria, também ele um pequeno passo na mesma caminhada, no qual fazia igual recensão e comentário críticos ao Esquisse d'une théorie de la pratique (Caria, 2003, 2004). 
A escolha deste livro, mais em particular, decorre também do facto de recentemente ter concluído um estudo sobre o Saber profissional (Caria, 2005a) para o qual mobilizei conhecimentos da sociologia da ciência sem ter dado, do meu ponto de vista, um adequado destaque à visão/posição de Pierre Bourdieu. Sendo assim, este texto será também uma forma de recusar, incluindo para mim próprio, uma "leitura relativista" do que tenho escrito sobre o conhecimento que se desenvolve no trabalho intelectual dos grupos profissionais (Caria, 2002, 2007a, 2005b).

\section{Uma interrogação racionalista sobre a ciência}

O livro em referência, Science de la science et réflexivité, é a edição de um curso no Collège de France, de Paris, sobre a temática referida em título. Nesta edição parecem ter sido preservados muitos dos exemplos e das ilustrações (inscritas entre parênteses rectos e em corpo mais pequeno na edição em referência) que na intervenção oral foram sendo inseridos em complemento às principais proposições teóricas. Como o próprio autor indica, o essencial do conteúdo da lição não é novo, porque retoma um artigo de 1975 que é relido e actualizado em função dos desenvolvimentos da sociologia da ciência dos anos 80 e 90 (Bourdieu, 2001: 91-95).

O prefácio e a introdução do livro (5-14) são bem elucidativos das intenções e interesses explícitos do autor: defender a autonomia da ciência contra os poderes da economia, da política e de todos os outros campos simbólicos, particularmente o campo filosófico que considera dominante na reflexão epistemológica sobre a ciência (21-22). A sua visão pretende afrontar explicitamente a atitude escolástica dos filósofos e de vários cientistas sociais ${ }^{1}$ que se centram apenas nos textos e nos discursos científicos e tomam a teoria científica formal como equivalente da prática científica, fazendo emergir concepções e significações irracionalistas (por serem contra a ciência) que são consideradas um perigo para os avanços históricos que a razão científica permitiu. Neste contexto, o autor reage muito criticamente a todas as abordagens que visam de modo radical relativizar a ciência ou evidenciar a especificidade epistemológica das Ciências Sociais (167-168), porque entende que todos os relativismos de inspiração pós-moderna visam nos seus efeitos destruir ou desacreditar o poder da ciência e, desta forma, dar mais poder ao económico ou ao político, ainda que possam explicitamente apenas visar uma luta simbólica pelo monopólio da verdade sobre o mundo social.

\footnotetext{
${ }^{1}$ Sobre a génese sócio-histórica da escolástica e das suas manifestações académicas, ver Bourdieu,
} 1998: 9-112. 
Para realizar este propósito, Bourdieu assume-se como um racionalista histórico: alguém que acredita/defende na/a razão científica com o propósito de desenvolver um conhecimento universal, partindo do pressuposto de que essa possibilidade não decorre de uma qualquer idealização do mundo científico, mas antes de uma prática e de uma história que autonomizaram este campo de outros poderes e lhe deram características sociais e cognitivas que o colocam à parte de outros campos simbólicos. Assim, mais do que uma convicção ou um ideário, as virtualidades da ciência como forma de conhecimento existem para Bourdieu porque foram produzidas pela sua história (produziram um campo com autonomia relativa) e estão incorporadas no inconsciente colectivo dos cientistas (o babitus científico).

Mas a defesa do poder científico na sociedade moderna ocidental, reivindicada por Bourdieu neste livro, não pretende iludir a arrogância, esquecer o dogmatismo científico ou ignorar que a razão da ciência, bem como de todos os campos simbólicos (filosofia, arte, etc.), começa por ser local e uma construção social, tendo a ciência a particularidade de ter conseguido tornar a sua verdade universal. Daí que Bourdieu pergunte, como questão central do livro: como é que é possível uma actividade situada historicamente, num tempo e num lugar social particulares, produzir verdade para além do seu local, enquanto conhecimento universal? A resposta, como veremos mais à frente, parte do raciocínio de que uma construção social torna-se realidade, e não é apenas mais uma interpretação, porque é capaz de gerar efeitos sociais de longo prazo (efeitos práticos e históricos) para além desse local e para além de si própria.

Do meu ponto de vista, esta pergunta é típica de um racionalismo socioconstrutivista que, para melhor se defender do relativismo epistemológico e do idealismo filosófico, adopta uma visão histórica. Mas será a versão histórica a única alternativa socioconstrutivista consistente ao relativis-

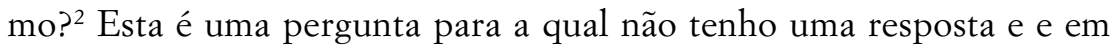
relação à qual espero que este texto possa ser uma pequena contribuição entre outras. $^{3}$

\footnotetext{
2 A dissociação entre o relativismo cognitivo e o socioconstrutivismo nem sempre é reconhecida nos textos que abordam estas temáticas no plano filosófico ou sociológico, porque se entende existir alguma ambiguidade no modo como o socioconstrutivismo se distancia do relativismo, dado ambas as correntes terem um visão muito semelhante sobre a história da razão científica. Dentro deste ponto de vista, de não dissociação das duas correntes, ver: numa abordagem sociológica, Dubois, 2001; numa abordagem filosófica, Echeverria, 2003. Inversamente, numa perspectiva que procura explorar a dissociação entre as duas correntes, ver Chalmers, 1994, e Stengers, 2000. ${ }_{3}^{3}$ Esta interrogação não é recente no meu trabalho de investigação pois já na tese de doutoramento que defendi em 1997 admitia como bom o "rótulo" de construtivo-racionalista para situar a orientação epistemológica que seguia (Caria, 2000: 5-28).
} 


\section{A prática e o poder da ciência}

O livro aparece organizado em três capítulos: no primeiro, faz-se uma pequena revisão da literatura sobre a sociologia da ciência, onde se critica o relativismo da "nova sociologia da ciência" e o normativismo do universo simbólico da "velha sociologia da ciência" de inspiração mertoniana (15-66); no segundo capítulo, desenvolve-se e explica-se a natureza, simultaneamente social e cognitiva, da actividade científica, procurando-se fundamentar a aparente trans-historicidade da ciência (67-166); e, no terceiro, concretiza-se esta natureza social e cognitiva, quanto à reflexividade científica nas Ciências Sociais (167-220). ${ }^{4} \mathrm{O}$ livro contém, ainda, uma pequeníssima conclusão de duas páginas que nada acrescenta de relevante ao seu conteúdo, salvo na indicação que dá para a necessidade de se ler um outro livro (de que eu faço uso neste texto) para melhor compreender a visão de Bourdieu sobre a ciência: Médiations pascaliennes5.

No capítulo 1, Bourdieu aceita as conclusões da nova sociologia da ciência particularmente no que se refere ao facto de esta trazer importantes contribuições empíricas para evidenciar que a ciência não é um conhecimento dogmático (dado ter uma história de institucionalização que evidencia a génese social da sua razão) e que tem um mundo social e conflitual próprio (onde se jogam partidas e disputas, que evidenciam os interesses e poderes sociais desiguais dos cientistas na ciência). Deste ponto de vista, entende que são um avanço científico relativamente à visão consensualista e a-histórica da abordagem mertoniana. Mas a seguir critica, por ser relativista, uma outra parte das conclusões da "nova sociologia da ciência" (as críticas incidem principalmente nos trabalhos de Bloor, Latour e Wollgar) em três aspectos que entende serem reducionistas da dinâmica do jogo científico: (1) não dão conta da dinâmica interna e histórica própria do campo científico; (2) apenas se referem a disputas locais em laboratórios; (3) concentram-se, em demasia, nas práticas e nos produtos escritos. Em alternativa, Bourdieu refere, contra estes reducionismos, que ao tomar-se por objecto o laboratório de investigação científica, ele não deve ser visto, por um lado, como fechado em si próprio, devendo-se dar conta da posição colectiva e individual (relativamente aos cientistas que nele trabalham e aos outros cientistas que trabalham noutros locais) que ocupam nas relações sociais que atravessam o campo científico respectivo. Por outro lado, deverá ser tomada em consideração a totalidade das práticas que produzem

\footnotetext{
${ }^{4}$ Neste texto não darei especial destaque à abordagem que Bourdieu faz da epistemologia das Ciências Sociais, porque o modo como a equaciona, no essencial e quanto às suas qualidades, nada a distingue das restantes ciências.

${ }^{5} \mathrm{Na}$ tradução em língua portuguesa o livro é intitulado Mediações pascalianas (Bourdieu, 1998).
} 
realidade e não apenas as práticas da escrita (que seria o ponto de vista típico da semiologia) que se organiza por relação aos textos científicos legítimos (exemplo, da análise da prática da escrita num artigo para uma revista científica).

A proposta de investigação de Bourdieu supõe que o laboratório, ou qualquer outro local de produção científica colectiva, possa ser tomado como um campo ou um subcampo científico (75) naquilo que tem de autónomo como recurso capitalizável para reproduzir um poder científico dentro de um jogo que é sempre conflitual e polémico e que está para além (embora não à parte) dos textos e dos discursos racionalizadores da prática científica (das convenções sociolinguísticas). A possibilidade, enunciada, de um local poder ser considerado como um campo social é algo que se nos apresenta como particularmente inovador no pensamento de Bourdieu, embora me pareça que tal hipótese só ganha pertinência, na teoria dos campos, se nos estivermos a referir a locais centrais ao campo científico. Outras alternativas serão, por exemplo, as que foram formuladas nos anos 90 em Portugal (total ou parcialmente fora do enquadramento da teoria dos campos sociais): (1) por Nunes (1996) na qual o local-laboratório é visto na dupla faceta de cognição situada e de acção investida em relações de poder científico, sendo a análise orientada para as (des)continuidades e tensões entre as escalas micro, nacional e global; (2) por Martinez, Ávila e Costa (1994) na qual se procura na análise do laboratório criar um "consenso teórico mínimo" entre a "velha" e as novas sociologias da ciência" em torno do valorizar da dimensão organizacional/institucional da ciência. ${ }^{6}$

Ainda dentro da mesma linha de raciocínio, Bourdieu faz uma releitura dos "trabalhos relativistas" desmistificando o denominado artificialismo da realidade científica e o interesse próprio do cientista na descoberta da verdade. Nesta desmistificação (que se prolonga pelo início do capítulo 2 do livro, 67-81) chama-se a atenção para três tipos de erros: (1) os relativistas são a inversão lógica do positivismo, porque supõem na sua crítica à ciência que só há ciência positivista (supostamente, todos os cientistas acreditariam que a realidade é um dado com sentido em si próprio); (2) os relativistas, apesar de poderem praticar o método etnográfico, não chegam a evidenciar compreender o olhar positivista do cientista - que seria a cultura nativa do laboratório - preferindo antes entregar-se apressadamente aos seus objectivos exclusivamente político-filosóficos de denúncia e descrença do/no conhecimento científico (151-152); (3) os relativistas participam nos limites

${ }^{6}$ Para melhor perceber a importância da dimensão organizacional no debate epistemológico em ciência social, ver também Pinto, 2001. 
de uma visão escolástica do conhecimento porque, ao desqualificarem o interesse egoísta do cientista na procura da verdade, podem alimentar perversamente a ideia de que alguma vez foi ou será possível haver uma razão humana pura e neutra, exterior aos interesses sociais existentes.

Estes três erros ocorrem porque, segundo Bourdieu, pressupõe-se que o campo científico não tem qualquer autonomia relativamente ao campo político e, logo, todas as lutas simbólicas, científicas ou filosóficas, incluindo as lutas dos relativistas contra os racionalistas, serão sempre analisadas apenas como lutas políticas baseadas em artifícios e convenções de linguagem. Como acrescenta, dizer que a realidade é uma construção social e dizer que ela se desenvolve com base em interesses egoístas nada acrescenta de novo, para aqueles que, como o autor, adoptam um ponto de vista bachelardiano e racionalista histórico na ciência. Resta, no entanto, chamar a atenção para que a visão bachelardiana é reconhecida como racionalista na interpretação de Bourdieu não só por ter uma visão histórico-construtivista, mas, principalmente, por fazer uma interpretação da história da ciência em que se evidencia o progresso e a melhoria da sua capacidade para explicar a complexidade do mundo.

Bourdieu recusa partir do pressuposto, sem problematização, de que exista falta de autonomia da ciência face à política, ou mesmo em relação à arte (81-82). O autor convoca-nos a pensar e a ver a realidade da ciência como uma forma de conhecimento que se pratica (de modo desigual conforme os tempos, os territórios e os espaços sociais) com uma especificidade própria e que, portanto, nos pode trazer um olhar (é apenas uma possibilidade histórica e não uma essência) que não é (não tem propriedades de sentido) equivalente(s) a qualquer outro olhar, comum ou erudito. É essa especificidade, de prática e de história, que se mostra ser capaz de validar um conhecimento local como conhecimento universal: produzir ciência sem ceder o seu ponto de vista a outros campos simbólicos (arte, política, filosofia, etc.).

Fica, assim, clara a recusa de Pierre Bourdieu em "estar na moda pós-moderna": em desenvolver qualquer ponto de vista inter-campos ou de género de conhecimento híbrido, a não ser o propriamente científico dentro das suas fronteiras específicas. Mas convirá não confundir este ponto de vista com uma concepção formalista e arrogante de ciência. A razão científica defendida por Bourdieu é submetida à teoria que desenvolve para o campo científico: a sua razão é histórica (portanto transitória) e é uma tomada de posição dentro do próprio campo científico, em coerência com a prática que desenvolve (tem um propósito de poder fazer ciência, de poder científico) e em luta contra outras epistemologias. Assim, submete-se a ser 
criticada a partir dos seus próprios instrumentos de pensamento. Torna-se auto-reflexiva e, portanto, pode ser crítica de si mesma, porque pode objectivar aquilo que tem de subjectivo. Essa é a tarefa a que se entrega no final do livro (parte final do capítulo 3: 184-220, designada de "auto-análise"), no qual se evidenciam as motivações, as condutas e as tomadas de posição que decidiram da sua trajectória sociocognitiva e teórica; reflexão que é contextualizada a partir da referência à sua origem e trajectória universitária na relação com o meio intelectual francês dos anos 50 e 60, frente ao estado de desenvolvimento das Ciências Sociais em França. ${ }^{7}$

No entanto, convirá desde já alertar os leitores para o facto de o tipo de reflexividade que Bourdieu propõe poder ser visto como uma forma de etnocentrismo epistemológico, porque a sua perspectiva vai sempre no sentido de tomar a teoria dos campos sociais como o padrão único de avaliação das restantes correntes teóricas, ${ }^{8}$ e não de ver as complementaridades e os limites das várias contribuições, ainda que dentro de princípios e regras do fazer sociológico relativamente contraditórios. Mais especificamente, Bourdieu defende que só a sua teoria social (a teoria dos campos sociais) pode constituir-se como uma reflexão plenamente científica, porque só ela poderia objectivar o sujeito da ciência (o sujeito da objectivação). Só ela permite uma auto-reflexividade científica porque, como explica e desenvolve no livro Mediações pascalianas, só ela é capaz de ser crítica do modo escolástico de pensamento relativo ao etnocentrismo epistemo-filosófico, de inspiração positivista ou inspiração semiológica. Assim, todos os outros modos de reflexão científica, protagonizados por cientistas, que não objectivem o sujeito da objectivação, isto é, que não usem a teoria dos campos como padrão de análise, estão condenados a serem considerados por Bourdieu como reflexividades subjectivistas: cedem terreno, nas lutas simbólicas, à filosofia por via de cumplicidades com a escolástica ou com o relativismo epistemológico.

Em conclusão, para Bourdieu existem várias teorias científicas sobre o mundo social, mas nenhuma conseguiu objectivar a subjectividade do seu ponto de vista, porque todas as teorias cedem lugar à filosofia na reflexão sobre o conhecimento científico. Pelo contrário, a sua prática e a sua reflexão faz (pode fazer?) ciência da ciência e não filosofia da ciência.

\footnotetext{
${ }^{7}$ Não irei aqui entrar no pormenor desta descrição pois ele é apenas ilustrativo da teoria dos campos. Não traz por isso qualquer novidade que não seja a de Bourdieu tomar por objecto de análise sociológica um sujeito individual que é o seu próprio "self social" (não o seu eu íntimo, privado e narcisista, como frisa e bem distingue). O mesmo tipo de lógica e objecto de análise pode ser encontrado em Mediações pascalianas, no qual o autor assume o propósito de explicar a sua teoria explicando o seu self teórico, científico e académico (Bourdieu, 1998: 1-8; 28-36).

${ }^{8}$ Para uma avaliação crítica da teoria dos campos, ver Lahire, 2001.
} 


\section{Uma reflexividade científica de centro}

Para melhor clarificar o seu ponto de vista sobre a ciência, Bourdieu entrega-se nas páginas 91 a 123 do capítulo 2 a uma redescrição dos conceitos de prática, habitus, campo, capital e estrutura, com o propósito de mostrar a sua pertinência para a análise sociológica da ciência e para a auto-reflexividade do sujeito científico. É nesta redescrição que vai identificar as características sociocognitivas da ciência e explicar porque entende ser esta forma de conhecer universal e não apenas local.

A primeira ideia que destacaria é a da existência histórica de uma autonomia científica. É a qualificação da ciência como socialmente autónoma (um campo social próprio) que permite afirmá-la como um conhecimento universal. Esta qualificação da ciência para se tornar uma possibilidade histórica, mais ou menos conseguida, tem por referência primeira o modo como no passado a ciência se constituiu e institucionalizou nas principais universidades dos países centrais do sistema capitalista mundial. Bourdieu não explicita este referencial social, mas é dele e a partir dele que fala.

O lugar e o uso da ciência fora deste mundo simbólico de agentes privilegiados (os cientistas e as instituições universitárias mais prestigiadas internacionalmente) não faz parte da reflexão da ciência da ciência que Bourdieu desenvolve. Assim, os modos e as lógicas de funcionamento das ciências em sociedades não centrais e os novos modos e lógicas da ciência global que hoje não passam pela hegemonia das universidades (Nunes, 2001a, 2001b, 2003; Santos, 2000, 2003) não só não fazem parte do seu objecto de análise como são sempre tomados como práticas exteriores ou parcialmente exteriores ao campo científico, tal como ele é conceptualizado pela teoria dos campos sociais. Explica-se por isso, implicitamente, que todo o uso social da ciência fora deste mundo simbólico de privilegiados é uma forma social incompleta e subdesenvolvida de conhecer que, supõe-se, para ter plena dignidade cultural, terá que replicar o modelo central e universitário de ciência.

Daqui decorre o risco de alguns leitores portugueses deste livro de Bourdieu interpretarem várias dos seus passos como idealizações da prática científica ou, no mínimo, explicações descontextualizadas, de tal modo elas não são correntes entre nós e por isso não têm suficiente visibilidade social em Portugal. Tentando evitar esse risco, irei destacar, de seguida, os outros aspectos específicos do campo científico que, ao serem explicados por Bourdieu, me parecem estar mais aquém de serem realizados no modo como as Ciências Sociais são vividas e reproduzidas em Portugal.

A segunda ideia que importa destacar, na construção do conceito de campo científico, é a de que, para este funcionar autonomamente, é preciso que os seus agentes (os cientistas) cultivem uma disposição de envolvimento 
e implicação nas suas actividades que os leve a crer (a cultivar a crença prática, o illusio) que o jogo científico é uma actividade séria (para ser levada a sério): supõe competências, realizações, produtos e polémicas que são desenvolvidos e avaliados pelas qualidades e critérios prático-cientícos e não por critérios relativos a outros jogos (políticos da política, económico-materiais, mediático-comunicacionais, pedagógico-didácticos, simbólico-filosóficos, comunitário-domésticos, etc). Isto é, as práticas e disputas científicas não são vividas pelos seus práticos como um "faz de conta" ou uma encenação para realizar interesses não científicos. Supõem que a realização prática das regras do fazer ciência que estão incorporadas num habitus não são vividas como obrigações e constrangimentos externos, mas antes como necessárias ao jogo social em que se está envolvido.

A consequência desta formulação é que o interesse prático pela teorização do mundo é (deve ser) sério e só tem (deve ter) recompensas nessa actividade quem tem a crença suficiente para levar a sério este jogo social. A existência de recompensas sociais dentro das instituições científicas para práticos descrentes (que encenam e que fazem de conta) no jogo científico leva necessariamente a que os critérios de desenvolvimento e avaliação dos desempenhos supostamente científicos não o sejam de facto e que, portanto, as instituições intituladas científicas dêem direito de acesso ao papel social de cientista a agentes que não têm as disposições para saber-estar ${ }^{9}$ nessa condição social.

É por isto que Bourdieu entende que quase toda a relativização da razão científica vai gerar e reproduzir descrentes e cépticos, práticos que não levam a sério a actividade, porque deixam de viver "encantados" com a ciência. Assim, diríamos que a relativização histórica da ciência poderá introduzir suficiente lucidez no jogo científico de modo a que, sem perder a crença na sua verdade, se possa mostrar que todas as construções científicas são transitórias e que, por isso, merecem ser desencantadas para não serem tomadas como totalmente desinteressadas e puras. ${ }^{10}$ Há, assim, do ponto de vista de Bourdieu, que promover uma reflexividade científica que desencante o mundo científico (contra a escolástica da razão pura, fixa e ortodoxa) sem destruir a suas virtudes sociocognitivas: a produção de uma verdade universal.

A terceira ideia que importa realçar é a de que as virtudes sociocognitivas do mundo científico decorrem de um funcionamento social em círculo fechado: os destinatários primeiros dos produtos científicos são os próprios

\footnotetext{
9 Para não confundir com saber-ser e saber-ter, ver Caria, 2007b.

${ }^{10}$ Bourdieu chega a afirmar que as crenças desencantadas da prática científica poderão assumir formas de hipocrisia colectiva (2001: 152). Esta formulação coloca-me muitas dúvidas quando à sua coerência relativamente ao illusio científico.
} 
cientistas, isto é, os avaliadores do jogo são ao mesmo tempo jogadores do mesmo jogo. Daí que as discordâncias e divergências teóricas mais acentuadas, para poderem sobreviver e vencer ortodoxias, tenham que pôr em causa as regras do jogo: tenham que pôr em causa os jogadores que são, simultaneamente, juízes do cumprimento das regras e por esta via pôr em causa parte das regras práticas de fazer ciência, ao pôr em causa o poder dos avaliadores.

Este fechamento do campo científico tem várias consequências, necessárias e potenciais. As necessárias são referidas por Bourdieu do seguinte modo: a primeira consequência é que, contrariamente ao que acontece com outros campos simbólicos (arte e política), o preço e o valor relativo dos produtos científicos são aferidos num mercado de bens simbólicos que não tem outros agentes ou instituições que não sejam científicos; a segunda consequência é que a polémica e a divergência teórico-científicas têm como denominador central de arbitragem o critério da realidade. Este critério faz com que não possa haver argumento válido que não se expresse através de uma linguagem que produza realidade: uma linguagem que, enquanto construção social e científica, toma por referência factos elaborados por vias teóricas, evidenciando-os como exteriores à consciência individual de cada cientista e, por isso, passíveis de serem corroborados, complementados ou refutados por outros cientistas que usem dispositivos teórico-metodológicos que estejam contextualizados no mesmo paradigma de ciência. ${ }^{11}$

A terceira consequência (esta potencial, porque não é explicitamente referida neste livro, mas que, como sabemos, está bem evidenciada na obra La distinction [Bourdieu, 1979]), é que a divergência teórica no campo científico não é imediatamente vista como uma diferença a excluir, porque os agentes situados neste campo cultivariam o gosto pela distinção, enquanto parte de uma disposição geral das classes sociais superiores nas relações com a cultura. Quem não arrisca distinguir-se é porque não quer correr o risco de a diferença poder ser sancionada negativamente e, deste modo, mostra que não tem uma disposição distinta necessária ao habitus científico: um gosto para cultivar um estilo diferente de uso do conhecimento (contestando, em parte, as regras do estilo legítimo), indissociável de um poder simbólico que permita que essa diferença não corra o risco de gerar a exclusão do seu autor.

\footnotetext{
${ }^{11}$ Esta formulação da relação entre teoria e realidade é muito polémica, porque coloca o problema, muito discutido na sociologia e filosofia da ciência, de saber se é possível haver (saber como ocorre?) comunicação e polémica (corroboração e refutação factuais) entre cientistas filiados em diferentes programas de investigação, ainda que contidos na mesma disciplina ou subdisciplina científica. Nesta lógica de perceber as produções científicas da realidade e as modalidades em que os mesmos dispositivos técnicos são manipulados nas relações entre diferentes disciplinas e subdisciplinas, veja-se o interessante trabalho de João Arriscado Nunes (2000) sobre a microscopia.
} 


\section{Um sujeito histórico colectivo}

Mas a autonomia do campo científico é relativa, porque, no âmbito dos territórios nacionais centrais ao sistema capitalista mundial, a ciência está na dependência do Estado e por isso depende, em parte, financeiramente deste, facto que pode limitar a sua autonomia. Destaco, assim, uma quarta ideia sobre o campo científico: é esperado que, para a plena realização do poder científico numa sociedade, ele esteja associado ao desempenho de cargos políticos nas organizações científicas que reforcem e confirmem simbolicamente o capital de competência científica possuído por aqueles que ocupam essas posições. Em consequência, Bourdieu entende que o capital científico se exprime em duas modalidades: o incorporado, decorrente das competências práticas de fazer e pensar, que permitem saber ser e ter uma autoridade científica legítima (que permite a entrada e a integração neste universo simbólico sancionada pelos pares mais velhos); o simbólico, que decide quem está em condições pelo prestígio possuído de participar e tomar posição nas lutas científicas (quem tem poder para decidir em cada momento histórico o que é ciência, como é que se faz e para quem se faz).

Caso estas duas modalidades de capital científico sejam coincidentes, pode admitir-se (Bourdieu não o refere explicitamente) que haverá condições para mais facilmente o capital científico poder ser reconvertido em capital político e, assim, os cientistas (enquanto cidadãos cientistas e não cidadãos políticos) serem um dos protagonistas centrais nas decisões públicas. ${ }^{12}$ Se ocorrer o inverso (e este parece ser o diagnóstico de Bourdieu para o caso da França dos anos 90) a hierarquia de autoridade de fazer ciência (competência científica) torna-se paralela à hierarquia simbólica das instituições científicas e, deste modo, o campo científico perde autonomia, tornando-se mais permeável às pressões políticas da política.

Duas observações críticas, julgo, podem ser feitas a Bourdieu quanto ao conceito de capital científico. A primeira é que existe um vazio no seu raciocínio (o qual, do meu ponto de vista, não chega a ser explicado), porque remete a regulação da autoridade/competência científica para os processos de globalização da ciência, enquanto o poder simbólico e prestígio na ciência permaneceria na dependência dos estados nacionais (113-114).

Ficamos, assim, no que se refere a um dos problemas teóricos mais candentes de hoje (relativo ao poder simbólico global da ciência na sociedade), sem ter uma explicação sobre o modo como se deu esta transformação da escala nacional para a internacional e, portanto, sem compreender o modo

12 Sobre a temática das fronteiras entre a ciência e a tecnologia e a decisão política (pública ou outra), ver Gonçalves, 1996 e 2000; e Martins e Garcia, 2003. 
como Bourdieu concebe a dinâmica do mercado de bens simbólicos científicos globais e a sua articulação com os mercados nacionais. ${ }^{13}$ Fica-se por uma certa ambiguidade, pelo menos no texto deste livro, pois tanto parece dar-se uma conotação positiva ao fenómeno da globalização científica, para fugir às pressões políticas e mediáticas sobre a ciência à escala nacional, como parece dar-se uma conotação negativa, porque ficaria mais exposta às pressões mercantis do capital económico global.

A segunda observação crítica é que não se enuncia a possibilidade de a coincidência entre as duas espécies de capital científico (competência prática e prestígio institucional) poder gerar um efeito conservador na estrutura das relações de poder, através de poderes paternalistas e de patrocinatos, que excluiriam, incorrectamente, jogadores sérios, mas heterodoxos, do campo científico (110-116). Esta hipótese não é formulada por Bourdieu, porque o modo como redescreve a sua teoria na prática científica leva-o a considerar que: (1) a mudança em ciência faz-se na intersecção interdisciplinar, valorizando-se a erosão das fronteiras entre ciências e o hibridismo teórico-metodológico (74-75; 128-134); (2) no campo científico (contrariamente ao que acontece nos processos de reprodução noutros campos sociais), nem sempre a estrutura de posições sociais ocupadas no campo determinam as competências práticas (o babitus) e as tomadas de posição (lutas simbólicas e prestígio no campo) (117-127). No campo científico, poderia haver um desfasamento, mediado pelo babitus, entre as posições sociais obtidas (estrutura simbólica do passado) e as tomadas de posição (disputas simbólicas do presente) ${ }^{14}$ resultante do facto de o reconhecimento da competência estar dependente do valor distintivo da originalidade do conhecimento. ${ }^{15}$

Este modo particular de o babitus se manifestar no campo científico é enunciado por Bourdieu na parte final do capítulo 2 (123-146) e, penso, está relacionado com o facto de se frisar, à luz dos trabalhos de Kuhn (38, 157), que a mudança científica (das regras do fazer ciência e das relações de poder dentro da ciência) ocorre, primeiro, de dentro do mesmo paradigma e não de fora. Uma visão que leva a considerar que o campo científico nas sociedades capitalistas centrais tem uma capacidade auto-reformadora,

\footnotetext{
${ }^{13}$ Uma pequena contribuição para começar a compreender o ponto de vista de Bourdieu sobre as relações científicas internacionais poderá ser encontrado em Bourdieu, 2002.

${ }^{14}$ Esta possibilidade teórico-metodológica é explicitamente referida por Bourdieu em Mediações pascalianas (Bourdieu, 1998: 137-144) e foi por mim assinalada como estando implícita na sua obra fundadora da teoria da prática (Caria, 2003: 139-141).

${ }_{15}$ Esta originalidade, convirá salientar, apresenta-se num primeiro momento como uma construção que pretende (pelos seus autores) ser reconhecida como um produto legítimo (dentro de um campo científico).
} 
sem necessidade de revoluções científicas dado estar-se, explícita ou implicitamente, sempre em permanente luta científica sobre as regras do fazer ciência. O próprio campo científico transforma-se, como refere, em sujeito bistórico (138-140). Fica, no entanto, uma pergunta em aberto: será que esta capacidade auto-reformadora da ciência é compatível com a descrição deste campo social (e de qualquer outro na teoria de Bourdieu) em que os agentes dominantes buscam, na luta simbólica, o monopólio do poder científico?

\section{Ficar pelo inconsciente científico?}

Algumas destas formulações levam-me a conclusões que, suponho, estão para além do pensamento de Bourdieu e que por isso, suspeito, teriam a sua discordância global. No entanto, do meu ponto de vista, não deixam de ser deduções lógicas daquilo que é enunciado. Vejamos, de seguida, uma síntese dos tópicos que consideraria mais relevantes.

A razão científica, para produzir verdade universal, supõe, para além da crença prática no jogo científico (participar a sério na actividade), duas outras disposições práticas no babitus científico: (1) uma disposição estética para a distinção, que permita recompensar simbolicamente a diferença sociocognitiva (a originalidade científica); (2) uma disposição ética (um ethos) para a arbitragem impessoal do capital científico, através da construção de evidências realistas (factos científicos) de prova e refutação, consequência do facto de os juízes científicos (os cientistas com maior poder simbólico) se auto-limitarem (no seu capital de competência e autoridade científica), aceitando discutir e negociar parte das regras do jogo científico, como única forma de garantir a despersonalização e a desparticularização da ciência (149). ${ }^{16}$

É claro que esta ética prática (ethos) não fica longe de um dos princípios normativos de funcionamento da instituição científica formulados por Merton, embora aqui com uma configuração mais histórica: um cepticismo organizado que parte de um interesse desinteressado (sem ser interesseiro e sem ser dissimulado) no qual as regras científicas (tal qual as regras jurídicas) estão acima das pessoas concretas e, portanto, das formas de autoridade carismática em espaços sociais domésticos ${ }^{17}$. Ora, é esta disposição

\footnotetext{
$\overline{16}$ Bourdieu parece recusar esta disposição ética que permitiria a coexistência de diferentes dispositivos teórico-metodológicos na mesma disciplina científica, porque, quando se refere à existência de pluralismo epistemológico nas Ciências Sociais, desqualifica-o, dizendo que se trata apenas de uma forma de contaminação da ciência pela ordem político-democrática (144). Assim, parece-me que o princípio de explicação da dinâmica de poder nos campos simbólicos, relativo às estratégias de busca do monopólio da verdade, é reafirmado também para o campo científico.

17 Potenciadoras do poder paternalista na ciência e dos patrocinatos científicos, que, como referimos atrás, poderão ocorrer nas formas institucionais de ciência que se apresentem como demasiado fechadas sobre si próprias.
} 
ética que duvido seja compatível com as estratégias práticas de monopolização do poder que são sempre evidenciadas na obra de Bourdieu, quando este se refere aos agentes sociais que ocupam posições de dominação nos campos sociais.

Em conclusão, dentro do etnocentrismo da razão científica (racionalista, universitária e central de Bourdieu) descobrimos que existem outras racionalidades (estética e ética interiores à ciência) que se terão constituído como necessárias para o desenvolvimento sócio-histórico da ciência. Logo, fica claro, que, para se desenvolver uma ciência com aspirações a gerar centralidade ${ }^{18}$ (a disputar posições centrais no campo), é necessário cultivar junto dos aprendizes da ciência o gosto por um conhecimento lúdico (levar a sério o jogo da exterioridade frente às urgências do real), por um conhecimento inovador (que dê distinção de si) e por um conhecimento auto-limitado (um avaliador que negocie e aceite transgredir, por acordo inter-subjectivo com os pares, parte das regras do jogo que defende).

Mas esta educação do gosto científico será sempre uma actividade inconsciente e apenas regulada pelo habitus? Será que ela se manifesta de um modo tão exclusivo, para não dizer elitista, que apenas a podem ter os que a aprendem de modo prático e incorporado? Num contexto histórico e social em que a ciência não ganhou (ainda?) suficiente autonomia científica (como parece acontecer em Portugal), deixar que nas aprendizagens, nas interacções sociais e nos contextos sócio-institucionais funcionem apenas os processos prático-inconscientes do habitus não será condenar-se à condição e ao destino social de não ser central? Nestas circunstâncias, creio ${ }^{19}$ que a relativização da razão científica (porventura mesmo a histórica) terá como efeito destruir a possibilidade de se gerar poder científico autónomo, porque, aparentemente, a reflexividade, proposta por Bourdieu, só pode gerar efeitos sociais relevantes na condição de o campo científico já estar constituído autonomamente: de já se ter produzido encantamento e fé social (moderna) na razão científica.

Daí que tenhamos que fazer apelo (enquanto estratégica projectada e não como estratégia prática) a um outro modo (menos inconsciente e menos

\footnotetext{
${ }^{18}$ Este seria o modo de produção científica geralmente designado como de tipo 1, que, por comparação com o mais recente, o de tipo 2, seria mais académico, menos tecnológico e mais autocentrado. Sobre esta temática ver Gibbons et al., 1994, e Nowotny et al., 2001. Em Portugal, para além das obras de Nunes e Gonçalves já referenciadas atrás, ver também os trabalhos de Oliveira, 2002, e de Caria, 2005a.

${ }_{19}$ Esta crença é um convite à polémica com aqueles que pensam reflexivamente as Ciências Sociais em Portugal.
} 
psicanalítico ${ }^{20}$ ) de aprender a usar (e a reflectir com) a ciência na ciência, que permita, agindo sobre a estrutura da relação social com o conhecimento, contrariar e minimizar a produção de cientistas ilegítimos: docentes universitários sem gosto pela ciência, em virtude de não terem as três disposições identificadas necessárias à afirmação de um poder científico relativamente autónomo. Supomos que este enunciado vai no mesmo sentido das propostas que Madureira Pinto (2001: 54-59) fez para a análise da organização da actividade científica: entende que há que ter uma ética reformadora dentro da ciência de modo a que os discursos científicos (e a sua análise idealizada ou céptica) tenham contextos de acção que evidenciem os seus efeitos sociais dentro do campo, nomeadamente no plano das condições institucionais e interactivas em que a prática científica ocorre. Julgo que esta orientação para a reflexão crítica dentro da ciência está completamente fora do quadro teórico de Bourdieu, dado ser proposta, por mim, de um lugar social semiperiférico donde, portanto, não se pode dar como evidente a capacidade auto-reformadora da ciência. No entanto, esta orientação reformadora é também de uma visão racionalista, dado pretender lutar pela autonomia do campo científico como forma de melhorar as condições sociais que permitem a existência e o desenvolvimento da razão científica.

Apesar de a explicitação deste projecto estratégico para o campo científico não caber nos objectivos deste texto, valerá a pena assinalar que, do meu ponto de vista, o seu desenvolvimento depende de uma problematização do conhecimento que não passa apenas pela teoria dos campos, ainda que não a exclua. Passa, como admite e valoriza Madureira Pinto (2001: 46-53), por uma abordagem fenomenológica da ciência, centrada nos usos do conhecimento científico desenvolvidos na prática científica. Esta orientação, suponho, ganhará com uma problematização que veja a actividade científica como uma cultura profissional de cientistas, na linha dos trabalhos que tenho desenvolvido sobre o saber dos grupos profissionais (Caria, 2000: 3-140; 2002; 2005b; 2007a). Julgo que ganhará, ainda, em assumir o risco (enunciado e recusado por Bourdieu neste livro) de reconhecer a especificidade epistemológica das Ciências Sociais, como parte de um propósito mais geral (que enunciei como meu na introdução deste texto) de se ser capaz de melhor teorizar a prática científica do método etnográfico.

\footnotetext{
${ }^{20}$ Digo psicanalítico, porque a auto-análise desenvolvida por Bourdieu é apresentada como uma explicitação do inconsciente que se organiza através de uma linguagem que descreve a subjectividade do autor com base nas categorias de pulsão e sublimação. Este modo de descrição é particularmente evidenciado em Mediações pascalianas e segue de perto a concepção de Gaston Bachelard quando considera que os processos de objectivação em ciência se defrontam com obstáculos epistemológicos que exigem catarses intelectuais (Bachelard, 2001: 167-170).
} 


\section{Referências bibliográficas}

Bachelard, Gaston (2001), A epistemologia. Lisboa: Edições 70 [1971].

Bourdieu, Pierre (1979), La distinction - la critique sociale do jugement. Paris: Minuit.

Bourdieu, Pierre (1998), Mediações pascalianas. Oeiras: Celta.

Bourdieu, Pierre (2001), Science de la science et réflexivité. Paris: Raisons d'Agir.

Bourdieu, Pierre (2002), "Les conditions sociales de la circulation internationale des idées", Actes de la Recherche en Sciences Sociales, 145, 3-8.

Bourdieu, Pierre (2003), "Participant Objectivation", The Journal of the Royal Anthropological Institute, 9, 281-294.

Caria, Telmo H. (2000), A cultura profissional dos professores - o uso do conhecimento em contexto de trabalho na conjuntura da reforma educativa dos anos 90. Lisboa: FCT/FCG

Caria, Telmo H. (2002), "O uso do conhecimento: os professores e os outros", Análise Social, 164, 805-831.

Caria, Telmo H. (2003), "Da estrutura prática à conjuntura interactiva: relendo o esboço de uma teoria da prática de Pierre Bourdieu”, Revista Crítica de Ciências Sociais, 64, $135-143$

Caria, Telmo H. (2004), "O conceito de prática em Bourdieu e a pesquisa em educação", Educação \& Realidade, XXVIII(1), 31-48.

Caria, Telmo H. (2005a), "Trabalho e conhecimento profissional-técnico: autonomia, subjectividade e mudança social”, in Telmo Caria (org.), Saber profissional. Coimbra: Almedina, 17-42

Caria, Telmo H. (2005b), "Os saberes profissionais técnico-intelectuais nas relações entre educação, trabalho e ciência”, in António Teodoro; Carlos Alberto Torres (orgs.), Educação Crítica E Utopia: perspectivas emergentes para o séc. XXI. Porto: Edições Afrontamento / São Paulo: Cortez Editora.

Caria, Telmo H. (2007a), "Itinerário de aprendizagens sobre a construção teórica do objecto Saber”, Etnográfica, 11(1), 215-250.

Caria, Telmo H. (2007b), "A Cultura Profissional do professor de ensino básico em Portugal: uma linha de investigação a desenvolver?”, Sísifo - Revista de Ciências da Educação, 03. Disponível em: http://sísifo.fpce.ul.pt.

Chalmers, Alan (1994), A fabricação da ciência. São Paulo: Editora UNESP.

Dubois, Michel (2001), La nouvelle sociologie des sciences. Paris: PUF.

Echeverria, Javier (2003), Introdução à metodologia da ciência. Coimbra: Almedina.

Gibbons, Michael et al. (1994), The New Production of Knowledge. The Dynamics of Science and Research in Contemporary Societies. London: Sage.

Gonçalves, Maria Eduarda (org.) (1996), Ciência e democracia. Oeiras: Celta.

Gonçalves, Maria Eduarda (org.) (2000), Cultura científica e participação pública. Oeiras: Celta. 
Lahire, Bernard (2001), Le travail sociologique de Pierre Bourdieu: dettes et critiques. Paris: La Découverte, 23-94.

Martinez, Margarida Senna; Ávila, Patrícia; Costa, António Firmino da (1994), “A tensão superficial: ciência e organização num centro de investigação”, Sociologia-Problemas e Práticas, 16, 75-109.

Martins, Hermínio; Garcia, José Luís (orgs.) (2003), Dilemas da civilização tecnológica. Lisboa: Imprensa de Ciências Sociais.

Nowotny, Helga et al. (2001), Re-thinking Science: Knowledge and the Public in a Age of Uncertainty. Cambridge: Polity Press.

Nunes, João Arriscado (1996), “A política do trabalho científico: articulação local, conversão reguladora e acção à distância”, in Maria Eduarda Gonçalves (org.), Ciência e democracia. Oeiras: Celta, 251-276.

Nunes, João Arriscado (2000), "Públicos, mediações e construções situadas da ciência", in Maria Eduarda Gonçalves (org.), Cultura científica e participação pública. Oeiras: Celta, 81-100.

Nunes, João Arriscado (2001a), “Teoria crítica, cultura e ciência: as espaço(s) e o(s) conhecimento(s) da globalização”, in Boaventura Sousa Santos (org.), Globalização: Fatalidade ou utopia?. Porto: Afrontamento, 297-338.

Nunes, João Arriscado (2001b), "Laboratórios, escalas e mediações na investigação biomédica. A oncobiologia entre o global e o local”, in João Arriscado Nunes; Maria Eduarda Gonçalves (orgs.), Enteados de Galileu? A semiperiferia no sistema mundial da ciência. Porto: Afrontamento, 33-75.

Nunes, João Arriscado (2003), "Um discurso sobre as ciências 16 anos depois", in Boaventura de Sousa Santos (org.), Conbecimento prudente para uma vida decente. Porto: Afrontamento, 57-80.

Oliveira, Luísa (2002), "Desafios à Universidade: comercialização da ciência e recomposição dos saberes académicos”, Sociologia - Problemas e Práticas, 34, 93-116.

Pinto, José Madureira (2001), "Ciências e progresso: convicções de um sociólogo", Cadernos de Ciências Sociais, 21-22, 33-69.

Santos, Boaventura de Sousa (2000), A crítica da razão indolente - contra o desperdício da experiência. Porto: Afrontamento.

Santos, Boaventura de Sousa (2003), "Para uma sociologia das ausências e uma sociologia das emergências", in B. S. Santos, Conbecimento prudente para uma vida decente. Porto: Afrontamento, 735-775.

Stengers, Isabelle (2000), As políticas da razão. Lisboa: Edições 70. 